Review

\title{
Cordotomy for Intractable Cancer Pain: A Narrative Review
}

Saba Javed, MD', Ashwin Viswanathan, $\mathrm{MD}^{2}$, and Salahadin Abdi, MD, $\mathrm{PhD}^{1}$

From: ${ }^{1}$ Department of Pain Medicine, The University of Texas MD Anderson Cancer Center, Houston, TX; '2Department of Neurosurgery, The University of Texas MD Anderson Cancer Center, Houston, TX

Address Correspondence: Salahadin Abdi, MD, PhD Department of Pain Medicine

The University of Texas MD

Anderson Cancer Center 1400 Holcombe Blvd, Unit 0409 Houston, TX 77030

E-mail: sabdi@mdanderson.org

Disclaimer: There was no external funding in the preparation of this manuscript.

Conflict of interest: Each author certifies that he or she, or a member of his or her immediate

family, has no commercial association (i.e., consultancies, stock ownership, equity interest, patent/licensing arrangements, etc.) that might pose a conflict of interest in connection with the submitted manuscript.

Manuscript received: 07-03-2019 Revised manuscript received: 10-07-2019

Accepted for publication: 10-14-2019

Free full manuscript: www.painphysicianjournal.com
Background: Cordotomy is an invasive procedure for the management of intractable pain not controlled by conventional therapies, such as analgesics or nerve block. This procedure involves mechanical disruption of nociceptive pathways in the anterolateral column, specifically the spinothalamic and spinoreticular pathways to relieve pain while preserving fine touch and proprioceptive tracts.

Objectives: The purpose of this review article is to refresh our knowledge of cordotomy and support its continued use in managing intractable pain due to malignant disease.

Study Design: This is a review article with the goal of reviewing and summarizing the pertinent case reports, case series, retrospective studies, prospective studies, and review articles published from 2010 onward on spinal cordotomy.

Setting: The University of Texas, MD Anderson Cancer Center.

Methods: PubMed search of keywords "spinal cordotomy," "percutaneous cordotomy," or "open cordotomy" was undertaken. Search results were organized by year of publication.

Results: Cordotomy can be performed via percutaneous, open, endoscopic, or transdiscal approach. Percutaneous image-guided approach is the most well-studied and reported technique compared with others, with relatively good pain improvement both in the postoperative and shortterm period. The use of open cordotomy has diminished significantly in recent years because of the advent of other less invasive approaches. Cordotomy in children, although rare, has been described in some case reports and case series with reported pain improvement postprocedure. Although complications can vary broadly, some reported side effects include ataxia and paresis due to lesion in the spinocerebellar/corticospinal tract; respiratory failure due to lesion in the reticulospinal tract; or sympathetic dysfunction, bladder dysfunctions, or Horner syndrome due to unintentional lesions in the spinothalamic tract.

Limitations: Review article included literature published only in English. For the studies reviewed, the sample size was relatively small and the patient population was heterogeneous (in terms of underlying disease process, duration of symptoms, previous treatment attempted and length of follow-up).

Conclusions: Cordotomy results in selective loss of pain and temperature perception on the contralateral side, up to several segments below the level of the disruption. The plethora of analgesics available and advanced technologies have reduced the demand for cordotomy in the management of intractable pain. However, some patients with pain unresponsive to medical and procedural management, particularly malignant pain, may benefit from this procedure, and it is a viable treatment option especially for patients with a limited life expectancy whose severe, unilateral pain is unresponsive to analgesic medications.

Key words: Cancer pain, cordotomy complications, cordotomy indications, intractable pain, open cordotomy, percutaneous cordotomy

Pain Physician 2020: 23:283-292 
( pinal cordotomy (also called spinothalamic tractotomy) is an invasive procedure for the treatment of intractable pain not controlled by conventional therapies, such as analgesics or nerve block. This procedure involves a mechanical or thermal disruption of nociceptive pathways in the anterolateral column, specifically the spinothalamic and spinoreticular pathways (1) to relieve pain while preserving fine touch and proprioceptive tracts. Since the first description of cordotomy in 1912 (2), the broader adoption of opioids, and later the introduction of interventional pain procedures, such as implantable pumps and spinal cord stimulators, have diminished the need for spinal cord ablation in the management of intractable pain (3). However, there is still a subset of patients with malignant pain unresponsive to medical and peripheral interventions who may benefit from cordotomy. The purpose of this article, a focused review, is to refresh our knowledge of cordotomy and support its continued use in the forefront of managing intractable pain due to malignant disease. We chose 2010 and after to be included in this review and not before as we wanted to focus on more contemporary articles on cordotomy, as these are the articles using modern techniques like computed tomography (CT) or endoscopic guidance.

\section{Methods}

PubMed search of keywords "spinal cordotomy," "percutaneous cordotomy," or "open cordotomy" was undertaken. The search was further narrowed by articles published in English. Subsequently, the search was sorted by publication year, starting with the most recent. Articles published in 2010 or later were reviewed and included in this literature discussion. The timeframe was chosen to review the most recent studies, and to provide a contrast between the original procedure/outcomes verses how the procedure has progressed over the years. Figure 1 displays the PubMed search criteria.

\section{History}

In 1912, Drs. William Gibson Spiller and Edward Martin (2) described the first "open" cordotomy for the treatment of pain due to a tumor of the lower spinal cord. Martin first visualized the spinal cord directly via thoracic laminectomy performed at the sixth through eight dorsal vertebrae. After opening the dura, he slightly lateralized the cord and used a thin-bladed, doubleedged cataract knife with an angled point (about 5-mm long) to incise the anterolateral column roughly 2 to 3 $\mathrm{mm}$ in length. Closure of the dura and overlying tissue was uneventful.

Pubmed search for "spinal cordotomy", "open cordotomy", OR "percutaneous cordotomy"

$\downarrow 256$ artides

Search narrowed for artides in English

$\downarrow 211$ articles

Sort articles from 2010 to current

45 artides

Reviewed each ar ticle

Fig. 1. Methods: description of the PubMed search process. 
Percutaneous cordotomy was later made possible by advances in fluoroscopy and electrical monitoring. In 1963, Mullan et al (1) pioneered a less invasive percutaneous technique using a strontium needle and fluoroscopic guidance. They inserted a 17-guage lumbar puncture needle between the $\mathrm{C} 1$ and C2 vertebrae at a 45-degree angle (Fig. 2). Under fluoroscopic guidance, the dura mater was punctured, and the needle was advanced to the anterior dura mater. The stylet was then removed, and an inactive strontiumyttrium needle was inserted. The needle was kept in place as the no. 17 sheath was pulled out. After measurements and placement confirmation, the inactive needle was withdrawn and replaced by an active needle, and the pain pathways were ablated by appropriate radiation exposure. One of the many advantages of this approach is that only a local anesthetic is needed. Further advances in intraoperative imaging (for example, fluoroscopy or (CT) and electrophysiological confirmation of the target have improved precision, and thus outcomes while decreasing complications.

\section{Anatomy and Rationale}

Somatic pain sensations, as well as touch and temperature discrimination, are conveyed by the anterior spinothalamic tract. Furthermore, discriminative touch and vibration senses are conveyed by the ipsilateral dorsal columns. The lateral spinothalamic tract has a somatotropic distribution, with fibers from higher levels (for example, the arm and chest) more ventromedial, whereas those from lower levels (for example, the leg and sacrum) lie dorsolateral.

Primary afferent pain fibers enter the spinal cord ipsilateral to the pain via the Lissauer tract, which contains axons from dorsal ganglion cells. These axons synapse on second-order neurons in either the substantia gelatinosa or the nucleus proprius, sending their axons across the anterior commissure to ascend in the contralateral fasciculus. The spinothalamic tract is the second-order pathway, transmitting information about cutaneous temperature and noxious stimula-

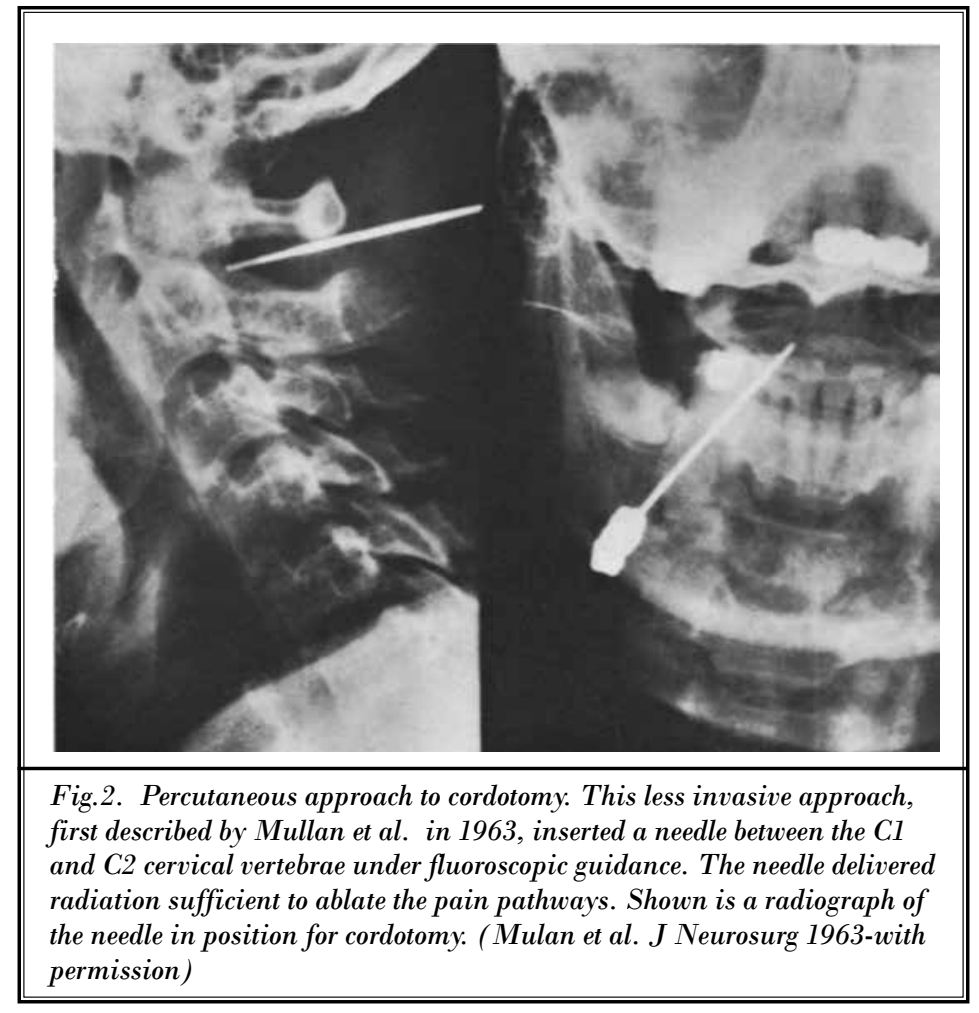

tion from the dorsal horn of the cord and synapsing in the ventral posterior lateral nucleus of the thalamus. The spinothalamic tract is the target by which cordotomy interrupts pain transmission. At a given spinal level in the spinothalamic tract, axons come from cells located in the contralateral cord 2 to 3 spinal segments lower because the Lissauer tract conducts pain fibers rostrally and ipsilaterally before they crossover to join the spinothalamic tract. Thus pain control with cordotomy is achieved 3 or 4 levels below the level of the lesion.

Extreme caution and precision must be employed when intervening in the upper cervical spinal cord because respiratory fibers of the reticulospinal tract lie just medial to the spinothalamic tract. If pain is bilateral, an open cordotomy in the thoracic region usually is recommended rather than percutaneous cervical cordotomy to avoid respiratory complications. Both the open and percutaneous approaches are discussed in this review.

The type of pain the patient is experiencing matters when considering cordotomy as a treatment option. Although most pain is transmitted through the anterolateral spinothalamic tract, some pain modalities, such as deafferentation pain, originate higher in the neural axis, and thus do not respond to cordotomy. In addition, types of pain that travel in the dorsal midline of the spinal cord, such as visceral pain, similarly will not respond to cordotomy.

\section{Clinical Applications and Patient Selection}

Cordotomy was a widely used neurosurgical procedure for 
chronic pain in the 1970s, when studies revealed that pain relief after cordotomy had a finite duration and was associated with extensive complications, including new deafferentation neuropathic pain, which was in some cases as severe as the original pain $(3,4)$. As a result, many neurosurgeons began to reserve cordotomy for patients with pain of malignant origin, whose shorter life expectancy would reduce the likelihood that the effects would wear off or new deafferentation neuropathic pain develop. There is no current consensus on patient selection or optimal timing for cordotomy. Patients with medically refractory, unilateral pain of malignant origin and with poor overall prognosis are likely to benefit the most from a cordotomy procedure.

Patients with unilateral pain in a dermatome below the shoulder are candidates for percutaneous high cervical cordotomy. Pain in the head or neck will not benefit from cordotomy, instead requiring either a mesencephalotomy or a trigeminal tractotomy. If, however, the pain is bilateral, high level cordotomy is not advisable to avoid lesioning the reticulospinal fibers. To minimize some risk, Raslan (5) described a percutaneous CT-guided transdiscal cervical cordotomy performed at C4-5 or C5-6 to avoid sleep apnea if the patient's pulmonary status is compromised. Risk is reduced in this approach by lesioning caudal to the exit of the phrenic nerve rootlets from the spinal cord.

\section{Contraindications}

Successful percutaneous cordotomy requires the patient to lie in the supine position, keeping their head and neck still for approximately 60 minutes. Patients with severe orthopnea, agitation, or inability to remain still may be poorer candidates for the procedure. Patients also must be able to reliably communicate their sensations during physiologic testing, and thus dementia or delirium is a contraindication. Furthermore, because both percutaneous and open approaches require puncturing the spinal cord, uncorrectable coagulopathy or thrombocytopenia are contraindications. Because the dura is punctured, another contraindication is a large intracranial mass, which could cause tonsillar herniation.

If concerns exist regarding the patients respiratory status, pulmonary function tests may be useful prior to cordotomy. A forced vital capacity in 1 second greater than $12 \mathrm{~mL} / \mathrm{kg}$ is considered sufficient respiratory reserve to undergo cordotomy. The spinal pathway controlling autonomic breathing lies in the anterolateral cord and is at risk for damage during cordotomy. Although this is usually not a prohibitive risk factor in unilateral cordotomy, the contralateral lung may be damaged because of disease burden and cannot support adequate respiration. Hence extreme caution must be employed in patients with impaired respiratory reserve. Furthermore, extreme caution should be exercised in performing bilateral high cervical cordotomy because of the potential for injury to the reticulospinal fibers in the anteromedial upper cervical cord that regulate spontaneous respiration. This procedure carries the risk of "Ondine's curse," also known as sleep-associated apnea or central hypoventilation syndrome. If a bilateral high cervical cordotomy is considered, the procedure should always be staged, and the lesions be offset so as to not be perfectly symmetrical.

\section{Technique}

\section{Open Technique}

For open cordotomy, the patient is administered general anesthesia and placed in the prone position. Access to the spinal cord is achieved by hemilaminectomy or full laminectomy contralateral to the pain at least 3 to 4 segments above the patient's pain. After dural opening, the dentate ligament is sectioned at the desired level. To allow exposure of the ventral cord, the free end of the dentate ligament is grasped, allowing the cord to be rotated away from the operative side. A 45-degree cordotomy hook is inserted into the anterolateral quadrant and swept ventrally. An angled dissector is then swept through the cut. The surgeon must use extreme caution to avoid disrupting the medial pia and injuring the anterior spinal artery.

\section{Percutaneous Technique}

Percutaneous cordotomy, which uses radiofrequency ablation to interrupt the pain pathway in the cord, can be performed with monitored light sedation and local anesthetic. Furthermore, this technique, unlike open cordotomy, allows the surgeon to stimulate the electrode prior to lesioning to confirm both presence within the spinothalamic tract and a safe distance from the corticospinal tract (6). Percutaneous cordotomy is performed with the patient lying supine, and can be performed either under fluoroscopic or CT guidance. As CT guidance provides a 3-dimensional (3D) perspective on the electrode position, this has become the favored technique for percutaneous cordotomy. Prior to the procedure, a lumbar puncture is performed to instill adequate intrathecal contrast medium to allow visualization of the cervical spinal cord. 


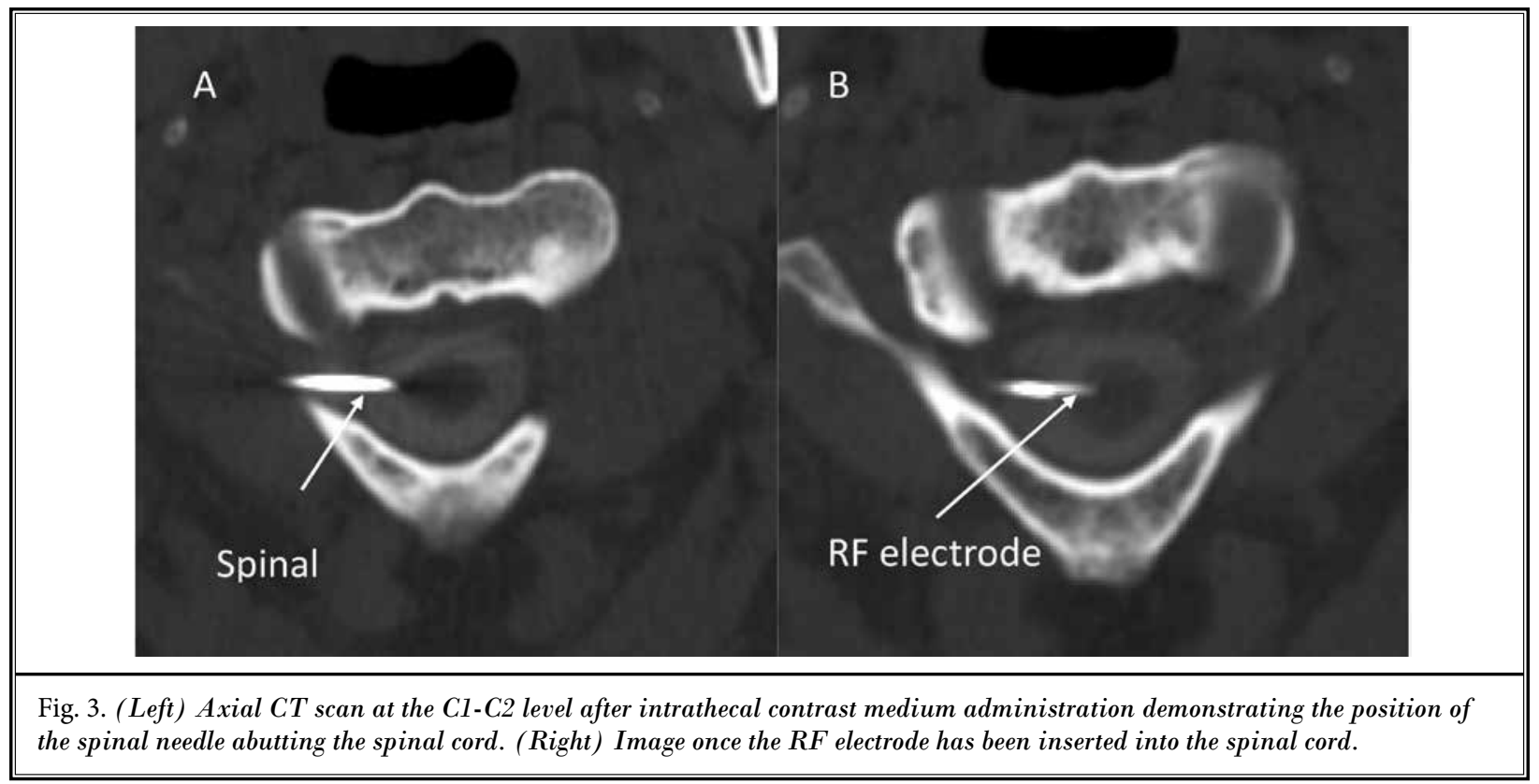

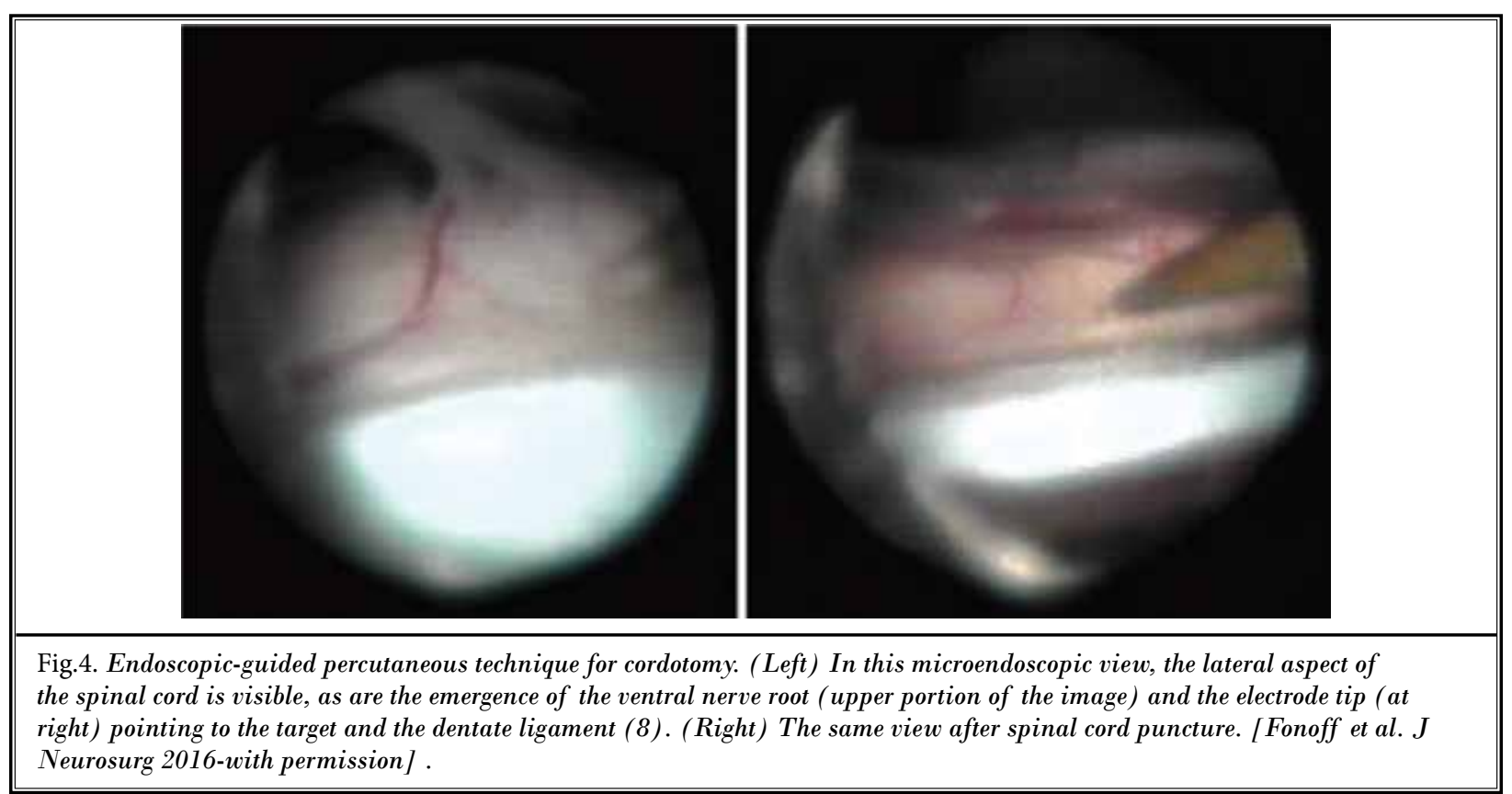

After local anesthetic is infiltrated into the skin and subcutaneous tissue, the needle is advanced under radiographic guidance. The goal is to position the spinal needle abutting the spinal cord (Fig. 3). To target pain in the lower extremity, the spinal needle is positioned $1 \mathrm{~mm}$ anterior to the antero-posterior midpoint of the spinal cord. For pain in the arm or chest, the needle is positioned $2 \mathrm{~mm}$ anterior to the midpoint of the spinal cord. When the spinal needle is abutting the spinal cord, a radiofrequency electrode is inserted through the needle, and entry into the cord is confirmed by impedance mapping. An increase in the impedance from approximately 300 ohms to more than 500 ohms signals penetration of the pia. The impedance is generally greater than $700 \Omega$ when inside the spinal cord, whereas it is less than $400 \Omega$ in the 
cerebrospinal fluid (7). Advancement of the electrode into the cord may induce pain. To approximate the distance to the corticospinal tract, a motor threshold is determined by low-frequency electrical stimulation. In contrast, high-frequency stimulation produces contralateral sensations and confirms the electrode is within the spinothalamic tract. During this electrical monitoring, the position of the radiofrequency electrode is adjusted to target the painful part of the body. Once in position, the tip of the needle is heated to $80^{\circ} \mathrm{C}$ for 60 seconds to interrupt the tract.

\section{Endoscopy-Guided Percutaneous Technique}

The initial approach is similar to that for the percutaneous technique. The guide cannula for a 17-gauge needle is advanced to the intradural space, and the endoscope inserted for visualization of the spinal cord and surrounding structures. The endoscope allows clear visualization of the pial surface of the spinal cord, in addition to the dentate ligament, arachnoid membrane, ventral and dorsal root entry zones, and blood vessels (Fig. 4). The electrode is inserted into the spinal cord at the midpoint between the dentate ligament and the ventral root entry zone. Advantages of endoscopic guidance include shortened fluoroscopy time and no need for contrast medium (8).

\section{Transdiscal Approach}

In a 2005 study, Raslan (5) discussed an anterior transdiscal approach at the C4-5 or C5-6 level (based on CT guidance) using water-soluble contrast medium. As already mentioned, performing the procedure below C4 or C5 (i.e., distal to the phrenic nerve root exit) is a way to avoid sleep apnea and/or pulmonary compromise. The patient lies in supine position in the CT scanner. The spinal needle is adjusted to enter the target disc space, and its positioning for the desired trajectory is confirmed by CT images. The needle trajectory is adjusted as needed to enter the anterolateral cord very close to the midline. On achieving a satisfactory trajectory, the needle is further carefully inserted to pass through the dura. The electrode is then inserted into the spinal needle while observing the impedance; entrance into the cord is confirmed by a rapid increase in impedance greater than 1,000 ohms. The electrode tip is inserted to a depth of 2 to $3 \mathrm{~mm}$.

\section{Complications}

Cordotomy complications vary broadly in the literature, although they have reduced substantially in the
CT-guided era. They are most often due to collateral lesions of the adjacent spinocerebellar and corticospinal tracts, and are manifested most frequently as ataxia or paresis, respectively. Fortunately, these effects remit spontaneously and rapidly in a significant percentage of patients $(2.9 \%-100 \%)$, whereas they are permanent in a small proportion (1\%-20\%) (9). Other known complications include acquired sleep apnea (10). A substantial proportion of patients $(0.5 \%-27 \%)$ experience severe respiratory failure in the era of open cordotomy, and an anterior transdiscal approach in the lower cervical region has been proposed as an approach to avoid this complication (5). Other complications may be due to unintended lesions of structures adjacent to the spinothalamic tract. There have been reports of patients developing sympathetic dysfunction, bladder dysfunction, or Horner syndrome (14).

Late onset of new pain following cordotomy is an especially pernicious complication, reported as occurring in $6 \%$ to $70 \%$ of patients who undergo cordotomy for unilateral pain. The new pain most often mirrors the initial pain, in the same location on the contralateral side. Nagaro et al (11) reported that 33 of 45 patients who underwent cordotomy experienced this new pain. In 28 of these patients, the location of the new pain echoed the original pain on the opposite side of the body; the new pain often could be abolished by blockade of the nerves subserving the original pain. Postcordotomy pain has been reported in various studies to affect $6 \%$ to $60 \%$ of patients $(11,12)$. Bowsher (13) suggested that the unilateral inhibition via cordotomy of nociceptive cells with naturally bilateral receptive fields is the cause of this pain. Higaki et al (22) speculated that the increased or new pain occurs through a referred pain mechanism. Their study of 26 patients with bilateral pain who underwent unilateral percutaneous cordotomy found that 19 of the patients (73.1\%) had pain after the procedure, which was as severe as the original pain in 14 patients. Of the 13 patients who underwent subsequent bilateral cordotomy, $7(53.4 \%)$ exhibited new postoperative pain, which was located cephalad to the region-rendered analgesic by cordotomy, and was more readily controlled than the original pain. These authors concluded that cordotomy is indicated for patients with bilateral pain because the postoperative pain may be more readily controlled then the original pain.

To reduce the frequency of these complications, somatosensory and motor evoked potentials have been employed. Jahangiri (21) described the use of intraop- 
erative neurophysiological monitoring for cordotomy using somatosensory evoked potentials and transcranial electric motor evoked potential during the procedure. Furthermore, some authors recommend against using cordotomy in noncancer patients, as the potential risk of complications is too high compared with the benefit.

\section{Outcomes}

\section{Percutaneous Cordotomy}

In most of the literature reporting cordotomy outcomes, percutaneous procedures were used. The key clinical studies on percutaneous cordotomy are summarized in Table 1. The success rates for pain relief in these reports are high, but the follow-up intervals are short. Bain et al (15) reviewed 45 patients with various cancer diagnoses (mesothelioma, head and neck, bronchial, esophageal, colon, pelvic, and rectal) who underwent percutaneous cordotomy and reported substantial pain reduction 2 days after the procedure (median score: 0 , interquartile range [IQR]: $0-5$ ) and 28 days after the procedure (median score: 0, IQR: 0-3.3). Kanpolat et al (16) reported 207 patients who underwent CT-guided percutaneous cordotomy for intractable pain, which was related to malignancy in 193 patients, such as pulmonary malignancies, mesothelioma, gastrointestinal tumors, and Pancoast tumor. The initial success rate of these procedures was $92.5 \%$. The same authors later reported on 108 cancer patients who underwent CT-guided percutaneous cordotomy for intractable pain and found $98.1 \%$ of the patients reported initial pain relief (17). In these patients, the minimum and maximum preoperative Kar-

Table 1. Percutaneous cordotomy: A systematic review, case studies and retrospective reviews.

\begin{tabular}{|c|c|c|c|c|c|}
\hline Authors & Study type & $\begin{array}{c}\text { Cohort } \\
\text { size }\end{array}$ & Technique & Pain type & Outcome \\
\hline $\begin{array}{l}\text { Raslan et al (9) } \\
2008\end{array}$ & Case series & $\begin{array}{l}51 \\
\text { patients }\end{array}$ & $\begin{array}{l}\text { Percutaneous CT- } \\
\text { guided radiofrequency } \\
\text { ablation }\end{array}$ & $\begin{array}{l}\text { Mesothelioma (47\%), breast } \\
\text { cancer }(9.8 \%) \text {, bronchogenic } \\
\text { cancer }(7.8), \text { Ewing/prostate/ } \\
\text { stomach cancer/Pancoast } \\
(19.6 \%), \text { other }(15.8 \%)\end{array}$ & $\begin{array}{l}\text { Patient-reported postcordotomy } \\
\text { initial and } 6 \text {-month rates of pain } \\
\text { relief } 98 \% \text { and } 80 \% \text {, respectively }\end{array}$ \\
\hline $\begin{array}{l}\text { Kanpolat et al } \\
\text { (16) } 2009\end{array}$ & Case series & $\begin{array}{l}193 \\
\text { patients }\end{array}$ & $\begin{array}{l}\text { CT-guided } \\
\text { percutaneous } \\
\text { cordotomy }\end{array}$ & $\begin{array}{l}\text { Pulmonary malignancies } \\
\text { (mesothelioma, Pancoast } 49.6 \%) \text {, } \\
\text { GI cancer (21.3\%), other (29.1\%) }\end{array}$ & $\begin{array}{l}\text { Initial postcordotomy success rate } \\
92.5 \%\end{array}$ \\
\hline $\begin{array}{l}\text { Kanpolat et al } \\
\text { (17) } 2013\end{array}$ & Case series & $\begin{array}{l}108 \\
\text { patients }\end{array}$ & $\begin{array}{l}\text { CT-guided } \\
\text { percutaneous } \\
\text { cordotomy }\end{array}$ & $\begin{array}{l}\text { Lung carcinoma (62\%), } \\
\text { mesothelioma }(24 \%) \text {, Pancoast } \\
\text { tumor }(13 \%)\end{array}$ & $\begin{array}{l}\text { Initial postcordotomy rate of pain } \\
\text { relief } 98.1 \%\end{array}$ \\
\hline $\begin{array}{l}\text { France et al } \\
\text { (20) } 2014\end{array}$ & $\begin{array}{l}\text { Systematic } \\
\text { review }\end{array}$ & $\begin{array}{l}160 \\
\text { patients }\end{array}$ & $\begin{array}{l}\text { Percutaneous cervical } \\
\text { cordotomy }\end{array}$ & $\begin{array}{l}\text { Mesothelioma-related cancer } \\
\text { pain }\end{array}$ & $\begin{array}{l}\text { Systematic review involving } 9 \\
\text { case studies totaling } 160 \text { patients; } \\
\text { greatest pain reduction at initial } \\
\text { postprocedure measurements; side } \\
\text { effects included headache, mirror } \\
\text { pain, motor weakness, respiratory } \\
\text { dysfunction (all rare); no deaths } \\
\text { directly related to cordotomy }\end{array}$ \\
\hline $\begin{array}{l}\text { Fonoff et al (8) } \\
2016\end{array}$ & Case series & $\begin{array}{l}24 \\
\text { patients }\end{array}$ & $\begin{array}{l}\text { Microendoscopy- } \\
\text { guided percutaneous } \\
\text { cordotomy }\end{array}$ & $\begin{array}{l}\text { Lung cancer }(33 \%) \text {, prostate } \\
\text { cancer }(25 \%) \text {, breast cancer } \\
(12.5 \%) \text {, SCC }(8.3 \%) \text {, other } \\
(21.2 \%)\end{array}$ & $\begin{array}{l}\text { Significant pain relief achieved in } \\
90 \% \text { of patients; } 2 \text { patients reported } \\
\text { transient ataxia }\end{array}$ \\
\hline $\begin{array}{l}\text { Bekar et al (18) } \\
2017\end{array}$ & $\begin{array}{l}\text { Retrospective } \\
\text { study }\end{array}$ & $\begin{array}{l}48 \\
\text { patients }\end{array}$ & $\begin{array}{l}\text { CT-guided high-level } \\
\text { percutaneous cervical } \\
\text { cordotomy }\end{array}$ & $\begin{array}{l}\text { Bronchogenic cancer }(41.6 \%) \text {, } \\
\text { colon cancer }(10.4 \%) \text {, } \\
\text { mesothelioma }(8.3 \%) \text {, Pancoast } \\
\text { tumor }(8.3 \%) \text {, other }(31.4 \%)\end{array}$ & $\begin{array}{l}\text { Mean precordotomy VAS score } 9.6 \text {; } \\
\text { postoperatively initial and } 6 \text {-month } \\
\text { scores } 3.6 \text { and } 6.8 \text {, respectively }\end{array}$ \\
\hline $\begin{array}{l}\text { Strauss et al } \\
\text { (19) } 2017\end{array}$ & $\begin{array}{l}\text { Retrospective } \\
\text { analysis }\end{array}$ & $\begin{array}{l}19 \\
\text { patients }\end{array}$ & $\mathrm{O}$-arm guided $\mathrm{PRFC}$ & $\begin{array}{l}\text { SCC (15.7\%), breast cancer } \\
(5.2 \%) \text {, lung cancer ( } 31.6 \%) \text {, GU } \\
(21 \%) \text {, GI }(5.3 \%) \text {, melanoma } \\
(5.3 \%) \text {, thyroid (5.3\%), sarcoma } \\
(5.3 \%) \text {, unknown }(5.3 \%)\end{array}$ & $\begin{array}{l}\text { Immediate relief obtained in } 94 \% \text {; } \\
\text { at } 1 \text { month, } 88 \% \text { were pain free }\end{array}$ \\
\hline
\end{tabular}

Abbreviations: GI, gastrointestinal; GU, genitourinary; PRFC, percutaneous radiofrequency cordotomy; SCC, squamous cell carcinoma. 
nofsky Performance Scale scores ranged from 20 to 70, whereas the postoperative scores ranged from 40 to 90 $(P<0.001)$. The median preoperative score on the Visual Analog Scale (VAS) pain score was 8 (range, 6-9), but this dropped to $0(P<0.001)$ on postoperative day 1 ; authors notate that long-term follow-up was inadequate in this study. Likewise, Raslan (9) reported on 51 patients with cancer-related pain who underwent percutaneous CT-guided cordotomy to ablate upper spinal cord pain pathways, and reported rates of initial and 6-month follow-up patient-reported pain relief of $98 \%$ and $80 \%$, respectively. In a retrospective study, Bekar et al (18) analyzed outcomes for 48 patients who underwent CT-guided high-level percutaneous cervical cordotomy, and found the mean preoperative VAS score was 9.6, which improved to 3.6 postoperatively; however, the 6-month follow-up mean VAS score was 6.8. Strauss et al (19) reported the use of O-arm-guided percutaneous cordotomy, which used both 2-dimensional fluoroscopy and $3 D$ reconstructed $C T$ imaging, with outcomes comparable to those reported in other studies.

France et al (20) published a systematic review of 9 studies comprising 160 patients who underwent percutaneous cervical cordotomy for intractable pain related to mesothelioma, which concluded that pain relief was good in the majority of patients. The good effect lasted in some patients up to 6 months (20). Complete pain relief was attained in $80.2 \%$ (73/91) of patients, whereas no pain relief was reported in $5.5 \%$ (5/91). The most frequent side effects were headache, mirrored contralateral pain, and motor weakness, but these were mostly transient. Finally in 2019, Viswanathan et al (30) published results from a trial in which patients were randomized to either undergo cordotomy or comprehensive palliative care. Those patients assigned to cordotomy experienced significant reduction in pain, whereas those patients randomized to continued palliative care did not improve. Furthermore, patients randomized to palliative care could crossover to the cordotomy arm, and all patients who elected to crossover also experienced significant reduction in pain.

\section{Open Cordotomy}

The key clinical studies on open cordotomy are summarized in Table 2. Cowie and Hitchcock (23) published a case series of 56 patients who underwent open cordotomy. In that series, $95 \%$ of those patients were pain free immediately after the procedure, but that this rate diminished to $55 \% 1$ year after the procedure (23). Tomycz et al (24) reported that 6 of 9 patients who underwent open thoracic cordotomy for severe, debilitating pain reported postoperative improvement in their pain level after a median follow-up interval of 31 weeks. The success rate for patients with nonmalignant pain was $85 \%$ initially, but it decreased to $35 \% 1$ year after the procedure, and $20 \%$ after 3 years (24). Hosking et al (25) described a patient with neuroendocrine tumor who underwent open bilateral cordotomy at T1/T2 after failure of intrathecal analgesia, and reported significant improvement in original pain in the lower extremities after the procedure, with only minor wound pain; lower limb strength remained intact. More recently, Steel et al (26) described 2 children, one with caudal regression syndrome and the other with neurofibromatosis, who underwent open thoracic anterolateral cordotomy with good pain relief. Patient 1 had substantial pain relief, unfortunately the patient died 12 weeks postcordotomy due to cancer-related illness.

Table 2. Open cordotomy case studies.

\begin{tabular}{|l|l|l|l|l|l||}
\hline \multicolumn{1}{|c|}{ Authors } & Study type & Cohort size & \multicolumn{1}{|c|}{ Technique } & \multicolumn{1}{c|}{ Pain type } & \multicolumn{1}{c|}{ Outcome } \\
\hline $\begin{array}{l}\text { Hosking et al } \\
(25) 2015\end{array}$ & Case report & 1 patient & $\begin{array}{l}\text { Open bilateral } \\
\text { cordotomy at T1/ } \\
\text { T2 postfailure of } \\
\text { intrathecal analgesia }\end{array}$ & Neuroendocrine tumor & $\begin{array}{l}\text { Postcordotomy significant improvement } \\
\text { in original pain (lower extremity) with } \\
\text { only minor wound pain; lower limb } \\
\text { strength remained intact }\end{array}$ \\
\hline $\begin{array}{l}\text { Tomycz et al } \\
(24) 2014\end{array}$ & Case series & 9 patients & $\begin{array}{l}\text { Open thoracic } \\
\text { cordotomy }\end{array}$ & $\begin{array}{l}\text { Cancer-related pain } \\
(44.4 \%), \text { postherpetic } \\
\text { neuralgia (22.2\%), spinal } \\
\text { cord injury (22.2\%), } \\
\text { multiple sclerosis (11.1\%) }\end{array}$ & $\begin{array}{l}\text { Six patients reported postcordotomy } \\
\text { improvement in pain after median follow- } \\
\text { up of 31 weeks }\end{array}$ \\
\hline $\begin{array}{l}\text { Steel et al (26) } \\
2017\end{array}$ & Case report & 2 children & $\begin{array}{l}\text { Open thoracic } \\
\text { anterolateral } \\
\text { cordotomy }\end{array}$ & $\begin{array}{l}\text { Caudal regression } \\
\text { syndrome (50\%), } \\
\text { neurofibromatosis (50\%) }\end{array}$ & $\begin{array}{l}\text { Immediate and significant postcordotomy } \\
\text { pain relief in both cases; one patient } \\
\text { discontinued opioid analgesia 8 weeks } \\
\text { after procedure; other patient remains } \\
\text { free of opioid analgesia 36 weeks after } \\
\text { procedure }\end{array}$ \\
\hline
\end{tabular}


Patient 2 was still doing well at 36 -month follow-up, with decreasing amount of opioid requirements.

\section{Cordotomy in Children}

Although open anterolateral thoracic cordotomy is an effective option for adults with intractable pain, it has seldom been reported in children. The key clinical studies in pediatric cordotomy are summarized in Table 3. Before the 2017 report by Steel et al (26) mentioned earlier, only 2 cases of open anterolateral cordotomy in children had been described; both had terminal neoplastic disease and underwent the procedure within 10 days before death $(27,28)$. The 2 children reported by Steel et al $(26)$ underwent open thoracic anterolateral cordotomy, and experienced effective pain relief with minimal adverse effects. As mentioned earlier, patient 1 had substantial pain relief, unfortunately the patient died 12 weeks postcordotomy due to cancer-related illness. Patient 2 was still doing well at 36-month follow-up, with decreasing amount of opioid requirements. The authors propose that their results support consideration of cordotomy as an option for management of intractable pain in children sooner rather than later, not delaying until death is imminent. The authors of this review caution the use of cordotomy for children until further reliable studies are done to show its short- and long-term effect.

\section{LIMITATIONS}

This is a review article with the goal of reviewing and summarizing the pertinent case reports, case series, retrospective studies, prospective studies, and review articles published from 2010 onward on spinal cordotomy. This timeframe was chosen to review the more recent literature and analyze the changes in procedural techniques and thus outcomes (if any). The authors realize that cordotomy is certainly an old interventional pain procedure, and as such setting a timeline for articles published after 2010 narrows the scope of the review. This was intentional, as the authors intended to review the original technique with the more recent literature.
Another limitation of this review article is the heterogeneous patient population from different regions of the world, various age groups, and a multitude of cancer diagnoses. Although cordotomy has shown positive outcomes in improving cancer-related pain, the sample size examined remains small, especially when narrowed down by cancer diagnoses or by pain location.

Finally, when discussing pain, one must be cognizant of the fact that pain is subjective. Furthermore, among the different studies reviewed in this article, various pain scales were used for pain assessment. Thus it is challenging to condense and summarize the results with different pain scales.

\section{Conclusions}

Cordotomy results in selective loss of pain and temperature perception on the contralateral side, up to several segments below the level of the disruption. The appropriate, aggressive use of opioids and introduction of neuromodulation strategies have reduced the need for cordotomy in the management of intractable pain. However, some patients with pain unresponsive to medical and procedural management, particularly malignant pain, may benefit from this procedure. Cordotomy is a reasonable treatment option for patients with a limited life expectancy whose severe, unilateral pain is unresponsive to analgesic medications. Research on cordotomy outcomes has shown that the procedure can provide meaningful pain relief, at least for short periods, although recurrence of pain and new pain that mirrors the original pain have been reported in numerous studies. The benefits and risks must be carefully weighed when considering cordotomy for patients with intractable pain, but for some patients the benefits continue to outweigh the risks. Today, spinal cord ablation is almost exclusively used for refractory cancer pain and in the palliative care setting, whereas neuromodulation remains a more robust long-term treatment for patients with refractory chronic pain.

Table 3. Pediatric cordotomy case studies.

\begin{tabular}{|l|l|l|l|l|l||}
\hline \multicolumn{1}{|c|}{ Authors } & Study type & Cohort size & \multicolumn{1}{c|}{ Technique } & \multicolumn{1}{c|}{ Pain type } & \multicolumn{1}{c|}{ Outcome } \\
\hline $\begin{array}{l}\text { Reddy et al } \\
(27) 2013\end{array}$ & Case report & 1 patient & $\begin{array}{l}\text { Percutaneous CT- } \\
\text { guided cordotomy }\end{array}$ & $\begin{array}{l}\text { Metastatic } \\
\text { medulloblastoma }\end{array}$ & $\begin{array}{l}\text { Postcordotomy improvement in pain; transient } \\
\text { dysesthetic pain resolved postoperative day 1 }\end{array}$ \\
\hline $\begin{array}{l}\text { Steel et al (26) } \\
2017\end{array}$ & Case report & 2 patients & $\begin{array}{l}\text { Open thoracic } \\
\text { anterolateral } \\
\text { cordotomy }\end{array}$ & $\begin{array}{l}\text { Caudal regression } \\
\text { syndrome (50\%), } \\
\text { neurofibromatosis } \\
(50 \%)\end{array}$ & $\begin{array}{l}\text { Immediate and significant postcordotomy pain } \\
\text { relief in both cases; one patient discontinued } \\
\text { opioid analgesia 8 weeks after procedure; other } \\
\text { patient remains free of opioid analgesia 36 weeks } \\
\text { after procedure }\end{array}$ \\
\hline
\end{tabular}




\section{References}

1. Mullan S, Harper PV, Hekmatpanah J, Torres H, Dobbin G. Percutaneous interruption of spinal-pain tracts by means of a strontiumgo needle. J Neurosurg 1963; 20:931-939.

2. Spiller W, Martin E. The treatment of persistent pain of organic origin in the lower part of the body by division of the anterolateral column of the spinal cord. JAMA 1912; 58:489-490.

3. Porter RW, Hohmann GW, Bors E, French JD. Cordotomy for pain following cauda equina injury. Arch Surg 1966; 92:765-770.

4. Jack TM, Lloyd J. Long-term efficacy of surgical cordotomy in intractable nonmalignant pain. Ann $R$ Coll Surg Engl 1983; 65:97-102.

5. Raslan AM. Percutaneous computed tomography-guided transdiscal low cervical cordotomy for cancer pain as a method to avoid sleep apnea. Stereotact Funct Neurosurg 2005; 83:159-164.

6. Tasker R. Textbook of Stereotactic and Functional Neurosurgery. New York, McGraw Hill, 1998.

7. Gildenberg PL, Zanes C, Flitter $M$, Lin PM, Lautsch EV, Truex RC. Impedance measuring device for detection of penetration of the spinal cord in anterior percutaneous cervical cordotomy. Technical note. J Neurosurg 1969; 30:87-92.

8. Fonoff ET, Lopez WO, de Oliveira YS, Teixeira MJ. Microendoscopy-guided percutaneous cordotomy for intractable pain: Case series of 24 patients. J Neurosurg 2016; 124:389-396.

9. Raslan AM. Percutaneous computed tomography-guided radiofrequency ablation of upper spinal cord pain pathways for cancer-related pain. Neurosurgery 2008; 62:226-233; discussion 233-234.

10. Tranmer BI, Tucker WS, Bilbao JM. Sleep apnea following percutaneous cervical cordotomy. Can J Neurol Sci 1987; 14:262-267.
11. Nagaro T, Adachi N, Tabo E, Kimura $S$, Arai T, Dote K. New pain following cordotomy: Clinical features, mechanisms, and clinical importance. J Neurosurg 2001; 95:425-431.

12. Nagaro T, Amakawa K, Kimura S, Arai T. Reference of pain following percutaneous cervical cordotomy. Pain 1993; 53:205-211.

13. Bowsher D. Contralateral mirror-image pain following anterolateral cordotomy. Pain 1998; 33:63-65.

14. Sanders $M$, Zuurmond W. Safety of unilateral and bilateral percutaneous cervical cordotomy in 80 terminally ill cancer patients. J Clin Oncol 1995; 13:1509-1512.

15. Bain E, Hugel $H$, Sharma M. Percutaneous cervical cordotomy for the management of pain from cancer: A prospective review of 45 cases. J Palliat Med 2013; 16:901-907.

16. Kanpolat $\mathrm{Y}$, Ugur HC, Ayten M, Elhan $\mathrm{AH}$. Computed tomography-guided percutaneous cordotomy for intractable pain in malignancy. Neurosurgery 2009; 64:ons187-ons193; discussion 193-194.

17. Kanpolat Y, Ozdemir M, Al-Beyati E. CT-guided percutaneous cordotomy for intractable pain in what is more than a disease: Lung malignancies. Turk Neurosurg 2013; 23:81-87.

18. Bekar A, Taskapilioglu MO, Eser P, Bilgin $\mathrm{H}$. CT-guided high-level percutaneous cervical cordotomy for intractable cancer pain. Turk Neurosurg 2017; 27:133-137.

19. Strauss I, Berger A, Arad M, Hochberg U, Tellem R. O-arm-guided percutaneous radiofrequency cordotomy. Stereotact Funct Neurosurg 2017; 95:409-416.

20. France BD, Lewis RA, Sharma ML, Poolman M. Cordotomy in mesothelioma-related pain: A systematic review. BMJ Support Palliat Care 2014; 4:19-29.

21. Jahangiri FR. Intraoperative neurophysiological monitoring (IONM) for cordotomy procedures. Neurodiagn ] 2015; 55:169-179.

22. Higaki N, Yorozuya $T$, Nagaro $T$, et al. Usefulness of cordotomy in patients with cancer who experience bilateral pain: Implications of increased pain and new pain. Neurosurgery 2015; 76:249-256; discussion 256; quiz 256-257.

23. Cowie RA, Hitchcock ER. The late results of antero-lateral cordotomy for pain relief. Acta Neurochir (Wien) 1982; 64:39-50.

24. Tomycz L, Forbes J, Ladner T, et al. Open thoracic cordotomy as a treatment option for severe, debilitating pain. J Neurol Surg A Cent Eur Neurosurg 2014; 75:126-132.

25. Hosking SP, Franco ME, Poon P, William L. Bilateral cordotomy post-failure of intrathecal analgesia in a palliative care setting. Intern Med J 2015; 45:586-587.

26. Steel D, Kirkman MA, Thompson DNP, Aquilina K. Open thoracic anterolateral cordotomy for pain relief in children: Report of 2 cases. J Neurosurg Pediatr 2017; 20:278-283.

27. Reddy GD, Okhuysen-Cawley R, Harsh $V$, Viswanathan A. Percutaneous CTguided cordotomy for the treatment of pediatric cancer pain. J Neurosurg Pediatr 2013; 12:93-96.

28. Queinnec E, Mouchel-Vielh E, Guimonneau M, Gibert JM, Turquier $Y$, Deutsch JS. Cloning and expression of the engrailed.a gene of the barnacle Sacculina carcini. Dev Genes Evol 1999; 209:180-185.

29. Atkin N, Jackson KA, Danks RA. Bilateral open thoracic cordotomy for refractory cancer pain: A neglected technique? J Pain Symptom Manage 2010; 39:924-929.

30. Viswanathan A, Vedantam A, Hess KR, et al. Minimally invasive cordotomy for refractory cancer pain: A randomized controlled trial. Oncologist. 2019; 24:e59o-e596. 